\title{
Long Lasting Insecticide Treated Net and Factors Limiting Effective Utilization in a High Malaria Incidence County of Wulu, South Sudan
}

\author{
Article by Gabriel O. Ayeni ${ }^{1}$, Okwuoma C. Abanobi ${ }^{2}$, Daniel O. Ebenezer ${ }^{3}$, Olagbegi M. \\ Oladapo $^{4}$ \\ ${ }^{1,3}$ Texila American University, Guyana, South America \\ ${ }^{2}$ Federal University of Technology, Owerri, Nigeria \\ ${ }^{4}$ Rhodes University, Grahamstown, South Africa \\ E-mail: ayenco_2@yahoo.com ${ }^{1}$
}

\begin{abstract}
Incidence of malaria disease is still very high in many areas of South Sudan which perhaps might be as a result of poor /noncompliance to preventive measures. The objective of this study was to investigate the use of LLITN, and factors limiting compliance to its utilization.

A case - control study was conducted among population in a typical County of South Sudan. A multistage random sampling technique was used; case-control matching was done. Information relating to access and use of LLITN was gathered and analyzed. Descriptive and inferential data analysis were carried out.

A total of 396 samples (cases 198 and control=198) were analyzed. The finding did not show satisfactory utilization of LLITN. Non-use of LLITN was significantly associated to the occurrence of malaria (OR=19.6, $C I=11.78-32.54), \quad p=)$. Poor understanding and not-taught how to use were significantly associated to the malaria occurrence (OR=4.6, 3.0; $C I=2.98-7.28,1.94-4.60 ; p=0.000)$ and year-round utilization of LLITN (OR=5.2, 3.9; CI=3.27-8.19, 2.49-6.18; $p=000)$. The finding showed poor LLITN retention and year-round use. There was significant association between factors promoting non-compliance and occurrence of malaria $(p=0.000)$. Also, finding showed care-giver level education is significantly associated to the use of LLITN $(p=0.000)$.

This study showed that the identified LLITN factors had significant association to its year-round regular use the regular use of LLITN and occurrence of malaria. Improving the use of LLITN remains important component especially in developing countries where resources to achieve simultaneous implementation of integrated malaria control programme could not be guaranteed.
\end{abstract}

Keywords: Malaria, Long Lasting Insecticides Treated Net, Non-compliance, Prevention, South Sudan.

\section{Introduction}

At the start of 2016, nearly half of the world's population was at risk of malaria. Malaria was considered to be endemic in 91 countries and territories in 2016, down from 108 in 2000. Most of the change can be attributed to the wide-scale deployment of malaria control interventions (WHO, 2016). According to the world malaria report 2016, South Sudan was among countries that has not achieved more than 20\% reduction in incidence and mortality between 2010 and 2015 (WHO, 2016). According to the estimates from World Health Organization (WHO, 2015), between 2000 and 2015, malaria incidence rates fell by $37 \%$ globally and malaria mortality rates fell by $60 \%$ (65\% in under five children) globally. With this reported declining trend in the incidence of Malaria diseases globally, available data from the DHIS could not support this in Wulu and some other counties in South Sudan. The possible factors for this needed to be investigated. Wulu is a typical County in South Sudan with a population of about 60,000. Majority of the inhabitants are Agrarian with some into crop, some into animal husbandry; others are artisan with few other doing office or white collar jobs. The area has recorded a consistent pattern of malaria in the last three years (DHIS 2014-2016). This consistent (and not downward) pattern of malaria 
DOI: $10.21522 /$ TIJPH.2013.05.04.Art061

ISSN: $2520-3134$

occurrence in the area makes it a good location for a study into factor promoting or limiting compliance to malaria preventive measures aside other socio-cultural and geographic similarities it shares in common with other counties of South Sudan.

Furthermore, the long lasting insecticide treated net, LLITN has been identified has major preventive tool which if well utilized could reduce the burden of malaria (WHO 2016, 2015; Pinch off et al (2016). However, most previous studies did not examine the factors which enhance the use of LLITN and factors which limit compliance to its regular use. There is therefore dearth of published data on factors promoting compliance and/or non-compliance to the use of LLITN. Meanwhile, if high incidence of malaria infection in areas of South Sudan is been reported (WHO, 2016), this could lend support to argument that there is prevalence of low level of compliance to the use of LLITN and other control measures. Clearly, there is need for further study in this direction bridge the knowledge gaps which still exist about control of Malaria/Severe Malaria occurrence in the area, in South Sudan generally and even globally.

This study was therefore directed investigate the utilization of LLITN in Wulu and to determine the factors promoting regular and year- round use of long lasting insecticide nets LLITN and also the challenges limiting compliance to utilization among the population.

\section{Methodology}

A Case-Control study design was utilized to study the LLITN risk factor of malaria/severe malaria and challenges to non/poor compliance with its utilization among population in Wulu County. The study population was drawn from male and female residents of Wulu County between the age of one year and sixty years. Cases definition: Malaria case definition: The Malaria condition tested and confirmed positive with the use of Rapid Diagnostic test kit, in addition to the presence of at least two of uncomplicated sign and symptoms noted as earlier mentioned. Rapid diagnostic tests (RDTs) for malaria offer the potential to extend accurate malaria diagnosis to areas when microscopy services are not available, such as in remote locations or after regular laboratory hours. Rapid malaria diagnostic tests have been developed in the lateral flow format (Ayele, 2012; WHO, 2013a). These tests use finger-stick blood, take only 10 to 15 minutes to complete, and do not require a laboratory (Wongsrichanalai, 2007). Severe malaria cases are those which had the presence of at least two signs and/or symptoms of malaria infection plus at least one sign and/or features of complication. They are tested with positive RDT result. Serum samples from much severe cases were further tested under microscope to screen for malaria and other diseases. Controls: Controls were subjects identified during the surveillance study period who have no history in the last 6 months of illness, and do not have malaria as at time the study was conducted i.e tested-Ve to RDT. Also the controls reside in the same geographic area as the cases. Cases and control must have been residing within Wulu County in the last one year. A multistage sampling technique was used to select the study samples. Confirmed cases and controls of malaria who met the inclusion criteria were investigated from the eleven different geographical locations. A simple random was thereafter used to select samples needed for the study. Selected cases were matched with controls with reference given to age and sex.

Minimum samples of 384 participants were selected for this study. The minimum sample size was calculated using the formula for observational studies. This was selected based on the population of each geographical area. $\mathrm{N}=\mathrm{P}(1-\mathrm{P}) \mathrm{Z}^{2} / \mathrm{D}^{2}$ (Araoye, 2004; Leslie and Kish 1965). Where $\mathrm{N}$ is the minimum sample size needed, $\mathrm{D}$ is the level of error that can be tolerated ( 0.05 chance of error), $\mathrm{P}$ is the estimated incidence rate (0.5) of malaria diseases, $\mathrm{Z}$ is the standard variate corresponding to the confidence level. At confidence level of $95 \%, \mathrm{Z}=1.96 \mathrm{~N}=0.5(1-0.5) 1.96^{2} / 0.05^{2} \mathbf{N}=\mathbf{3 8 4}$

Secondary data from the DHIS was also carefully extracted covering Jan 2014 and December 2016. The secondary data from the DHIS was used to evaluate the pattern and distribution of Malaria cases between January 2014 and December 2016. A-semi-structured questionnaire was designed and the interviewers used it to obtain the needed information on malaria risk factors, challenges to noncompliance with use of LLITN, and also socio-demographic data. Section A of the questionnaire was used to collect data on socio-demographic characteristic while section B will focus of LLITN risk factor 
for malaria and possible factors limiting compliance to known and effective use of LLITN. Data were collected and the field research assistants made effort to ensure reliability of the information gathered. Household and environment assessment was carried out by the field research assistants. Data analysis was done using the Statistical package for Social Science (SPSS) version 21. Data was analyzed using descriptive statistics of mean, frequencies, percentages, and presented with bar charts, pie charts. Inferential statistics of Pearson Chi Square and two by two contingency tables were used to test for association. Statistical level of significance p-value was set at 0.05 .

\section{Result}

A total of 396 samples (198 cases and 198 controls) were analyzed for this study. The finding of this study showed significant association between the occurrence of malaria disease and the identified risk factors of long last insecticide treated nets, LLITN ( $\mathrm{p}<0.05)$ (Table 1-2). Also association was found between factors promoting non/poor compliance to known effective preventive measure of LLITN and occurrence of Malaria. Presented in the Figures 1 and 2 are the data of participant who reported receipt of LLITN within the last one year and those who still retain for use as at study time. The finding showed relatively high percentage of the population does not retain the LLITN beyond a peak malaria season, and many did not receive and did not have money/means to get. Hence many do not have it as at study time. Also presented in Table 3 was the finding of analysis which tested for association between occurrence of severe malaria and LLITN factors; poor understanding of use and non-use throughout year was found to be significantly associated. Furthermore, the finding of association was found between year round utilization and some identified factors (Table 4 and 5, Figure 3). Educational status of care-giver or responsible person was found to be associated with utilization.

Table 1. Association between malaria disease occurrence and LLITN factors

\begin{tabular}{|l|l|l|l|}
\hline Variable & $\begin{array}{l}\text { Chi square } \\
\text { value }\end{array}$ & Df & P-value \\
\hline Have LLITN & 95.375 & 2 & 0.000 \\
\hline Awareness of LLITN benefit & 28.838 & 6 & 0.000 \\
\hline Taught on use & 34.296 & 2 & 0.000 \\
\hline Understand use & 86.723 & 10 & 0.000 \\
\hline Use regularly & 159.125 & 2 & 0.000 \\
\hline Reason for not using regularly & 173.791 & 8 & 0.000 \\
\hline Usage throughout year & 135.011 & 4 & 0.000 \\
\hline Household use regularly & 63.252 & 2 & 0.000 \\
\hline House reason for not using & 71.719 & 8 & 0.000 \\
\hline Household use throughout year & 74.320 & 4 & 0.000 \\
\hline Perception on prevention & 19.118 & 4 & 0.001 \\
\hline $\begin{array}{l}\text { Other reasons for not using LLITN } \\
\text { regularly }\end{array}$ & 173.791 & 8 & 0.000 \\
\hline
\end{tabular}

Table 2. Risk factors odd ratio for malaria occurrence

\begin{tabular}{|l|l|l|l|l|l|}
\hline Variable & Response & $\begin{array}{l}\text { No Mal } \\
\mathbf{\%}\end{array}$ & $\begin{array}{l}\text { Yes Mal } \\
\mathbf{\%}\end{array}$ & Odd Ratio & 95\% CI \\
\hline Have LLITN & Yes & 66.8 & 33.2 & 11.5 & $6.66-19.991$ \\
\hline & No & 14.8 & 85.2 & & \\
\hline $\begin{array}{l}\text { Taught on LLITN } \\
\text { use }\end{array}$ & Yes & 59.4 & 40.6 & 3.0 & $1.939-4.600$ \\
\hline & No & 32.9 & 67.1 & & \\
\hline Use LLITN regularly & Yes & 81.7 & 18.3 & 19.6 & $11.781-32.544$ \\
\hline
\end{tabular}


DOI: $10.21522 /$ TIJPH.2013.05.04.Art061

ISSN: $2520-3134$

\begin{tabular}{|l|l|l|l|l|l|}
\hline & No & 18.6 & 81.4 & & \\
\hline $\begin{array}{l}\text { Understand LLITN } \\
\text { use }\end{array}$ & Yes & 63.9 & 36.1 & 4.6 & $2.987-7.218$ \\
\hline & No & 27.6 & 72.4 & & $3.539-8.373$ \\
\hline $\begin{array}{l}\text { Household use } \\
\text { regularly }\end{array}$ & Yes & 69.1 & 30.9 & 5.4 & \\
\hline & No & 29.1 & 70.9 & & \\
\hline
\end{tabular}

Table 3. LLITN risk factors odd ratio for SEVERE malaria occurrence

\begin{tabular}{|l|l|l|l|l|l|}
\hline Variables & Response & $\begin{array}{l}\text { Mild-mod } \\
\text { Mal \% }\end{array}$ & $\begin{array}{l}\text { Severe Mal } \\
\text { \% }\end{array}$ & $\begin{array}{l}\text { Odd } \\
\text { Ratio }\end{array}$ & 95\% CI \\
\hline Have LLITN & Yes & 55.1 & 44.9 & 1.5 & $0.824-2.537$ \\
\hline & No & 45.9 & 54.1 & & \\
\hline Aware of LLITN Benefit & Yes & 52.1 & 47.9 & 1.7 & $0.786-3.771$ \\
\hline & No & 38.7 & 61.3 & & \\
\hline Taught on LLITN use & Yes & 59.6 & 40.4 & 2.3 & $1.286-4.020$ \\
\hline & No & 39.6 & 60.4 & & \\
\hline Understand LLITN use & Yes & 62.5 & 37.5 & 2.5 & $1.405-4.447$ \\
\hline & No & 40.0 & 60.0 & & \\
\hline $\begin{array}{l}\text { Use LLITN regularly (6-7 } \\
\text { days/week) }\end{array}$ & Yes & 61.1 & 38.9 & 1.7 & $0.830-3.627$ \\
\hline & No & 47.5 & 52.5 & & \\
\hline Use LLITN Throughout Y & Yes & 68.6 & 31.4 & 2.6 & $1.177-5.569$ \\
\hline & No & 46.0 & 54.0 & & \\
\hline $\begin{array}{l}\text { Household use regularly (6- } \\
7 \text { days/week) }\end{array}$ & Yes & 51.6 & 48.4 & 1.1 & $0.604-1.990$ \\
\hline & No & & & & \\
\hline
\end{tabular}

\section{Proportion of LLITN \\ recipients in the last 12 months}

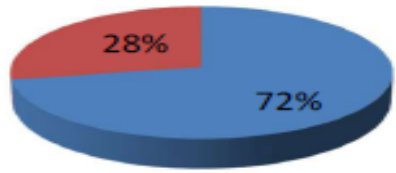

Receieved

LLITN

- Did not receive

Figure. 1. Proportion of participants who received LLITN in the last 12 months. 


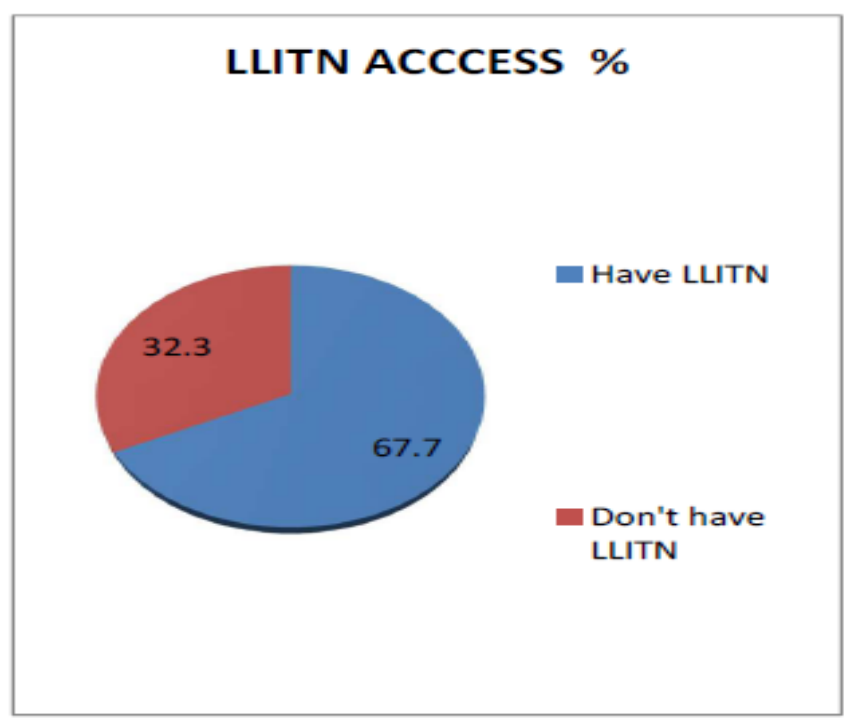

Figure 2. Proportion of participants who received have as at study period

Table 4. Association between regular LLITN utilization (year round YR-RD) and identified predisposing factors for use/non-use

\begin{tabular}{|l|l|l|l|}
\hline Variable & $\begin{array}{l}\text { Chi square } \\
\text { value }\end{array}$ & Df & P-value \\
\hline Have LLITN & 95.048 & 1 & 0.000 \\
\hline Awareness of LLITN benefit & 20.129 & 1 & 0.000 \\
\hline Taught on LLITN use & 36.545 & 1 & 0.000 \\
\hline Understand use & 53.029 & 1 & 0.000 \\
\hline $\begin{array}{l}\text { Use LLITN regularly (6-7 } \\
\text { days/week) }\end{array}$ & 196.536 & 1 & 0.000 \\
\hline
\end{tabular}

Table 5. LLITN use (Year Round) and identified predisposing factors for use/non-use

\begin{tabular}{|l|l|l|l|l|l|}
\hline Variables & Response & $\begin{array}{l}\text { Use LLITN } \\
\text { regularly } \\
\text { (YR-RD) \% }\end{array}$ & $\begin{array}{l}\text { Don't use } \\
\text { regularly } \\
\text { (YR-RD) \% }\end{array}$ & Odd Ratio & $\begin{array}{l}\text { 95\% } \\
\text { Confidence } \\
\text { Interval CI }\end{array}$ \\
\hline Have LLITN & Yes & 62.3 & 37.7 & 14.6 & $7.833-27.310$ \\
\hline & No & 10.2 & 89.8 & & \\
\hline Aware of benefit & Yes & 48.9 & 51.1 & 9.9 & $2.969-32.920$ \\
\hline & No & 8.8 & 91.2 & & \\
\hline Taught on LLITN use & Yes & 56.6 & 43.4 & 3.9 & $2.485-6.180$ \\
\hline & No & 25.0 & 75.0 & & \\
\hline Understand LLITN use & Yes & 59.8 & 40.2 & 5.2 & $3.266-8.191$ \\
\hline & No & 22.4 & 77.6 & & $19.972-$ \\
\hline $\begin{array}{l}\text { Use LLITN regularly } \\
\text { (6-7days/week) }\end{array}$ & Yes & 80.7 & 19.3 & 35.5 & 62.981 \\
\hline & No & 10.6 & 89.4 & & \\
\hline
\end{tabular}


DOI: $10.21522 /$ TIJPH.2013.05.04.Art061

ISSN: $2520-3134$

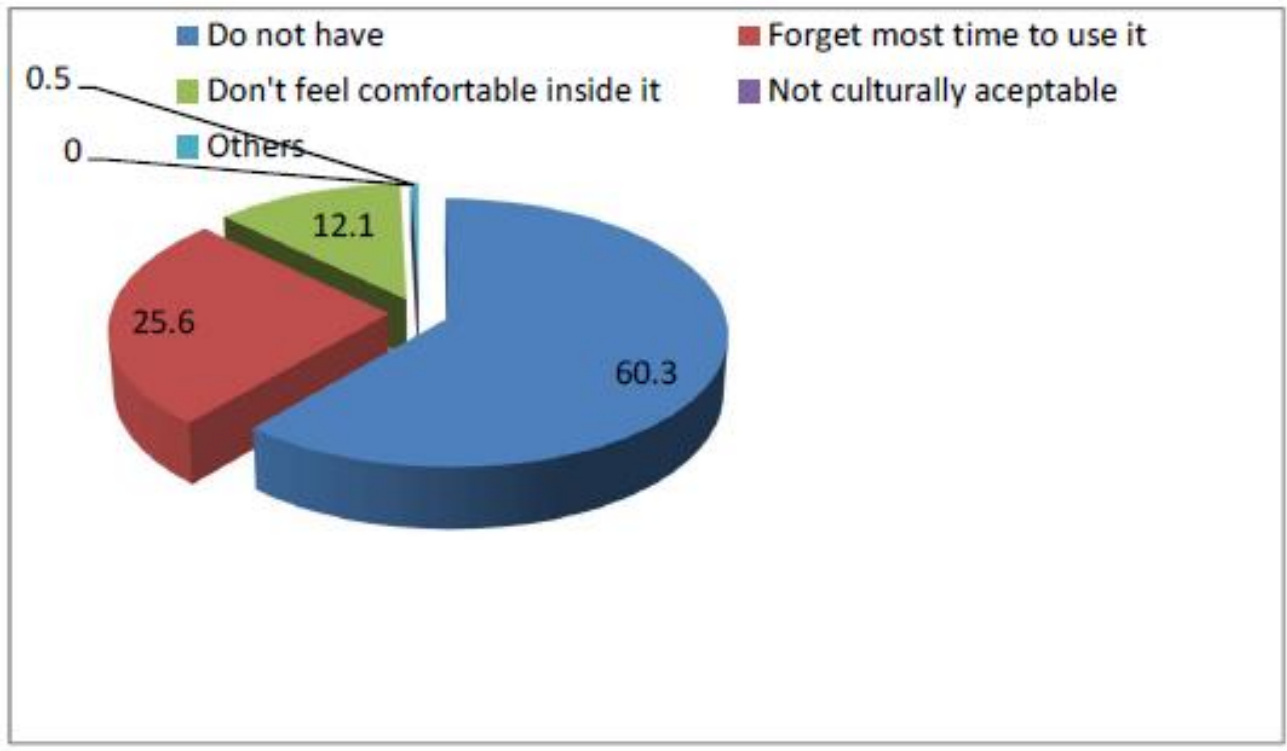

Figure 3. Reason for Non-utilization of LLITN \%

Table 6. Association between LLITN utilization and socio-demographic variables

\begin{tabular}{|l|l|l|l|}
\hline Variable & Chi square value & Df & p-value \\
\hline $\begin{array}{l}\text { Age (Responsible/home } \\
\text { care giver) }\end{array}$ & 12.294 & 8 & $\mathbf{0 . 1 3 9}$ \\
\hline Gender & 0.112. & 2 & $\mathbf{0 . 9 4 6}$ \\
\hline Marital status & 3.041 & 4 & $\mathbf{0 . 5 5 1}$ \\
\hline Educational status & 144.567 & 8 & $\mathbf{0 . 0 0 0}$ \\
\hline
\end{tabular}

Presented in Figure 4 is the trend/pattern of malaria occurrence across the three years of 2014 to 2016. There appeared to be a consistent pattern of occurrence during the period.

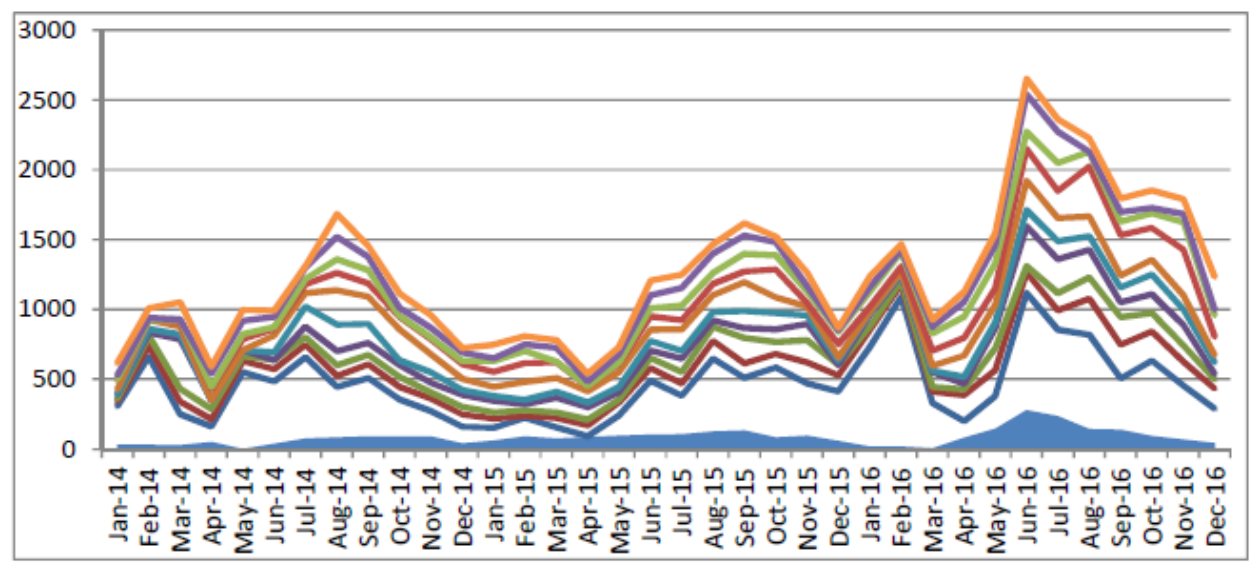

Figure 4. Pattern/trend of malaria incidence (time -occurrence -series) - january 2014-december 2016

\section{Discussion}

This study aimed to determine the factors influencing or limiting the utilization long lasting insecticide treated net LLITN and its effect in the control of malaria in a population with high incidence of malaria diseases. South Sudan is listed among nations where malaria control programme is ongoing (WHO 2016). The finding is therefore pertinent to better understanding of possible factors limiting the achievement of 
set malaria control programme objectives. It provided an avenue to suggest the possible areas needing more attention. The finding of this study identified LLITN non-use as significant risk factors for malaria disease occurrence $(O R>1, p<0.05)$. Despite seasonal rainfall, perennial transmission of malaria continues in Wulu county region. This could be attributed to some of the risk factor especially the poor compliance to year round use of LLITN by individual and household and incomplete/poor treatment of previous episode of malaria. The finding of Pinch off et al (2016) which studied individual and Household Level Risk Factors Associated with Malaria in Nchelenge District showed use of LLITN as a major factor to preventing malaria. It supported the findings of Musoke et al (2015) in their demonstration study that as the households continued to use many of the malaria prevention methods in the integrated approach which include sleeping under long-lasting insecticidal nets, screening in windows and ventilators, remove mosquito breeding sites, and ensure closing of doors early in the evening, they really benefited as revealed through observed reduction in mosquitoes indoors and malaria occurrence. While all the factors of LLITN had significant odd ratio to the occurrence of malaria, $(O R>1, p<0.05)$, the factors of not been taught, poor understanding of use and not using throughout the year had significant association to the occurrence of severe malaria. Poor understanding of the use of LLITN, non use of LLITN throughout the year were found as key risk factor for severe malaria following the regression analysis. Previous studies recommended the need to understand how local knowledge, belief and practice might influence the effectiveness of interventions set out in the control programmes (Deressa et al, 2014; Ajala and Wilson, 2013; Adongo et al, 2005). This study finding of poor timing in the distribution of LLITN and low retention of LLITN for future / continuous use was significant to achieving effective LLITN utilization. Although LLITN were usually distributed freely to the targeted groups of the population, many could not afford to buy in some instances where they could not get it free. The finding of cost (lack/inadequacy of fund) as a factor for poor compliance suggests the possible role of poverty in the control effort to reduce malaria and its effect. This is in support of finding from other studies (Ayele et al, 2012; Sintasath, 2005).

This study finding further confirmed LLITN use as a factor which could prevent malaria occurrence. It equally established some factors which could influence its use. In order to achieve more success, identified compliance limiting factors has to be addressed. The findings of poor timing in the distribution of LLITN and low retention of LLITN for future / continuous use by the participants need be looked into to improve utilization and resource management. Even among those who have LLITN, regularity of use which guarantees effectiveness was not there.. Furthermore, according to finding of Pinch of et al (2016), age of the participants was highly associated with RDT positivity, in particular among children aged 5 and 15 years. Children in this age category are at increased risk of malaria and are least likely to use interventions such as LLINs (Atieli et al 2011; WHO, 2013b); more attention is given to younger children and women (>pregnant women). This present study examined if there would be association between age of responsible person for the study participants or care givers and occurrence of Malaria; no association was found. However there was finding of association between occurrence of Malaria and the educational status of responsible person/care givers. The observed low level of education in the area and even in most part of South Sudan is a factor of interest that needs urgent and full attention in other to influence positive changes faster. Safeukui-Noubissi et al (2004) in their study found maternal education and possession of good knowledge about malaria as factor capable of reducing the risk of malaria especially among children. Other studies found association between occurrence of malaria and care-giver level of education (Roberts and Matthews, 2016; Snyman et al, 2015; Erhart et al, 2005).

Furthermore, programmes aiming to improve both maternal health and maternal education may reduce the incidence of severe malaria in children and should therefore be more advocated in Wulu and in areas with similar epidemiological patterns for malaria. More should also be done in the area of improving access to quality education. The timeliness of LLITN distribution and quality of malaria education and LLITN use training should be reviewed to enhance population understanding which was found to be significantly associated with utilization. This study finding showed significant association of the risk factor of LLITN with the occurrence of malaria/severe malaria disease occurrence. The existence of 
DOI: $10.21522 /$ TIJPH.2013.05.04.Art061

ISSN: $2520-3134$

ranging gaps must be filled if the controlled objective is to be achieved and on time also (WHO, 2013c). There is a need for change in the manner and approach with which issues surrounding Malaria control was been handled especially as it relate to the utilization of LLITN. This study limitation includes its inability to segregate utilization by age and gender.

\section{Conclusion}

The results of this study showed significant association between the occurrence of Malaria and availability, utilization, transfer of knowledge and understanding of the use of LLITN. The participants' understanding of LLITN use, were found to be significantly associated with severe Malaria. This study finding confirmed LLITN non-use as a risk factor for malaria/severe malaria and identified some of the challenges preventing compliance to utilizing it. New strategy to effective LLITN distribution, LLITN and Malaria knowledge sharing should be developed to further strengthen the malaria control efforts in the area and other areas with similar malaria occurrence pattern, geographical and socio-demographic status. Further study is recommended to look at non-compliance factors of other preventive measures among the population.

\section{Acknowledgement}

The authors thank the county health department team for their support to this study as part of the capacity effort of the county health workforce. We thank Mrs Elizabeth A. Ayeni who proof read this manuscript.

\section{References}

[1].Ajala, A S and Wilson, N A. (2013): Local Aetiology and Pathways to Care in Malaria among the Ibibio of South-coastal Nigeria; Health, Culture and Society 4, 1:102 DOI 10.5195/hcs.2013.102.

[2].Adongo P.B, Kirkwood B, Kendall C (2005): How local community knowledge about malaria affects insecticide-treated net use in northern Ghana; J. Trop Medi Intt Health 10, 4: 366-378 DOI: 10.1111/j.13653156.2005.01361.x

[3].Araoye MO (2004): Sample Size Determination in Research Methodology with Statistics for Health and Social Sciences $1^{\text {st }}$ ed. Ilorin: Nathadex Publishers; 2004. p. 115-21.

[4].Atieli H, Zhou G, Afrane Y, Lee M, Mwanzo I, Githeko A, et al. (2011): Insectice Treated Net (ITN) Ownership, Usage, and Malaria Transmission in the Highlands of Western Kenya. Parasites and Vectors 4: 1-10. pmid:21205315

[5].Ayele D.G, Zewotir T.T, Mwambi H.G (2012): Prevalence and risk factors of malaria in Ethiopia; Malaria Journal, 11:195 https://doi.org/10.1186/1475-2875-11-195

[6].Deressa W., Yihdego Y.Y, Kebede Z, Batisso E, Tekalegne A. and Dagne G.A (2014): Effect of combining mosquito repellent and insecticide treated net on malaria prevalence in Southern Ethiopia: a cluster-randomised trial; Parasites \& Vectors 7:132 https://doi.org/10.1186/1756-3305-7-132

[7].Erhart A, Thang N.D, Van Ky P., Thi Tinh T., Van Overmeir C, Speybroeck N, Obsomer V, Xuan Hung L, Khanh Thuan L, Coosemans M. and D'alessandro U. (2005): Epidemiology of forest malaria in central Vietnam: a large scale cross-sectional survey; Malaria Journal; 4:58 https://doi.org/10.1186/1475-2875-4-58

[8].MOH (2015): Zambia National Malaria Indicator Survey 2015. Lusaka, Zambia: Ministry of Health MOH Government of the Republic of Zambia. [Pinchoff J, Chaponda M, Shields TM, Sichivula J, Muleba M, Mulenga M, Kobayashi T, Curriero FC, Moss WJ (2016): Individual and Household Level Risk Factors Associated with Malaria in Nchelenge District, a Region with Perennial Transmission: A Serial Cross-Sectional Study from 2012 to 2015; Southern Africa International Centers of Excellence for Malaria Research. PLoS One. 11(6):e0156717. doi: 10.1371/journal.pone.0156717. eCollection 2016.

[9].Roberts D. and Matthews G. (2016): Risk factors of malaria in children under the age of five years old in Uganda Malaria Journal; 15:246 https://doi.org/10.1186/s12936-016-1290-х

[10]. RoSS (2009): Ministry of Health Malaria indicator survey report, Republic of south Sudan. 
[11]. Safeukui-Noubissi I, Ranque S, Poudiougou B, Keita M, Traoré A, Traoré D, Diakité M, Cissé MB, Keita MM, Dessein A, Doumbo OK.(2004): Risk factors for severe malaria in Bamako, Mali: a matched case-control study. Microbes Infect.6(6):572-8.

[12]. Sintasath DM, Ghebremeskel T, Lynch M (2005): Malaria prevalence and associated risk factors in Eritrea. Am J Trop Med Hyg. 72: 682-687.

[13]. Snyman K, Mwangwa F, Bigira V, Kapisi J, Clark TD, et al. (2015): Poor housing construction associated with increased malaria incidence in a cohort of young Ugandan children. Am J Trop Med Hyg; 92:1207-13.

[14]. WHO (2013a): Malaria rapid diagnostic test performance. 2009-2011: World Health Organization http://www.who.int/tdr/publications/documents/rdt3.pdf

[15]. WHO (2013b) World Malaria Report 2013. World Health Organization. http://www.who.int/malaria/publications/world_malaria_report_2013/en/

[16]. WHO (2013c): Country Cooperation strategy at a glance: belize. Geneva: World Health Organization; 2013. http://apps.who.int/iris/handle/10665/136963

[17]. WHO (2015): World Malaria Report WMR 2015: Regional and Country profile World Health Organization http://www.who.int/malaria/publications/world-malaria-report-2015/report/en/

[18]. WHO (2016): World Health Organization; Malaria. Intern. travel and health; visited 1st Oct, 2016. http://www.who.int/ith/en/

[19]. Wongsrichanalai C, Barcus MJ, Muth S, Sutamihardja A, Wernsdorfer WH (2007): A Review of Malaria Diagnostic Tools: Microscopy and Rapid Diagnostic Test (RDT). Am J Trop Med Hyg, 77 (Suppl 6): 119-127. 